

\title{
Ecología crítica contemporánea
}

\author{
Contemporary Critical Ecology \\ Ecologia crítica contemporânea
}

\section{Graciela Montaldo}

COLUMBIA UNIVERSITY, ESTADOS UNIDOS

Profesora del Departamento de Español y Portugués de Columbia University, Nueva York. Doctora en Letras por la Universidad de Buenos Aires. Ha escrito artículos y ensayos para libros y revistas internacionales, $\mathrm{y}$ ha editado varios volúmenes colectivos, entre ellos The Argentina Reader (Duke University Press, 2002; con Gabriela Nouzeilles). Entre sus libros se cuentan De pronto, el campo. Literatura argentina y tradición rural (Beatriz Viterbo Editora, 1993), La sensibilidad amenazada. Fin de Siglo y Modernismo (Beatriz Viterbo Editora, 1994), Ficciones culturales y fábulas de identidad en América Latina (Beatriz Viterbo Editora, 1999), A propriedade da Cultura (Chapecó, 2004), Zonas ciegas (Fondo de Cultura Económica, 2010) y Museo del Consumo. Archivo de la cultura de masas en Argentina (Fondo de Cultura Económica, 2016). Correo electrónico: gm2168@columbia.edu

Ensayo

Documento accesible en línea desde la siguiente dirección: http://revistas.javeriana.edu.co

doi:10.11144/Javeriana.cl21-41.ecco 
QUisiera Plantear aLgunas preguntas sobre el contexto disciplinario e institucional en que desarrollamos nuestro trabajo. En un momento de profundo cambio en nuestra relación con los saberes, vale la pena discutir cómo configuramos nuevos objetos de estudio; cómo nos colocamos ante la nueva difusión de la escritura académica y ensayística; qué nuevos interlocutores creamos con nuestro trabajo, especialmente desde el punto de vista de las humanidades (y su transformación a partir de la experiencia digital e intermedial).

Creo que hay una cifra del problema en nuestra relación con la temporalidad. El término obsolescencia se asocia primariamente con la obsolescencia programada de la tecnología, que implica el consumo ininterrumpido de nuevos dispositivos, pero, en términos generales, se trata de una práctica que involucra los modos de consumo en su conjunto. La obsolescencia se convirtió en una forma cultural de relacionarnos con los objetos pero también con la inmaterialidad. Y, de hecho, la cultura se volvió abiertamente un objeto de consumo, sometida al mismo régimen de obsolescencia, recambio, novedad, que rige a los demás productos de los que nos rodeamos.

En 2014 se distribuyó The History Manifesto de Jo Guldi y David Armitage. No digo se publicó porque se trata de un libro Open Access que comenzó a circular por la web como un manifiesto, como lo que sus autores definen como un "llamado a las armas". El argumento del libro se basa en un diagnóstico: "Un fantasma recorre nuestro tiempo: el de la corta duración (short term)". En este horizonte del corto plazo los autores, historiadores, ven un rechazo u olvido o negación de la longue durée. Y llaman a armarse contra el cortoplacismo que nos impide pensar desde todos los elementos que nos proporciona la experiencia histórica y, por tanto, tomar decisiones sobre los problemas comunes: el medio ambiente, las migraciones, la pobreza. La corta duración es el espacio en donde la obsolescencia tiene lugar; en donde se desintegran los sentidos, aquello que nos sumerge inevitablemente en un eterno presente. Sin embargo, vivir inmersos en el corto plazo, aquel lapso que bien sea más largo o más breve podemos nombrar como lo contemporáneo, no es necesariamente vivir a ciegas del espesor de la historia; es, también, habitar una singularidad. Los historiadores proponen la reconsideración de marcos en donde lo contemporáneo someta su singularidad a un régimen de sentido, de interpretación. Me interesaría aquí tomar un camino opuesto al de la búsqueda de sentidos y enfocarme en el tránsito dentro mismo de lo contemporáneo; habitar el tiempo presente con la conciencia del cambio como problema de la experiencia cotidiana, lo que podríamos frasear como la politización del tiempo. La sugerencia proviene de George Didi-Huberman, cuando propone volver a la historia, no a la larga duración (del pasado), tampoco a su 
simulacro (el corto plazo), sino, por el contrario, al instante, a la cristalización y rapidez de una imagen de cine; a lo contemporáneo que trama una relación compleja con el tiempo.

\section{Leer y escribir}

Ubicados en este umbral, creo que hoy resulta interesante preguntarnos por cómo nos relacionamos con nuestra propia práctica, sujeta, como cualquier otra en la contemporaneidad, a la exposición de un tiempo acelerado. Si todo está sometido hoy a la obsolescencia; si el término en que nos movemos es la corta duración, ¿cómo trabajar con materiales que pertenecen al archivo; que fueron codificados en el libro a través de la escritura; que interpusieron con lo efímero del presente una inmaterialidad hecha de valores y tradición? Me pregunto qué clase de objetos constituyen hoy nuestras bibliotecas, materiales y virtuales, reconvertidas en archivos. La mayoría de los críticos, entrenados en literatura, nos fuimos inclinando hacia otras opciones desde principios de los años 9o. No fue solo presión de la aparición de los estudios culturales en Inglaterra y en Estados Unidos. Esa presión, que sin duda existió, quizás vino a canalizar una insatisfacción muy presente ya en los años 9o: la insatisfacción con las disciplinas tal como continuaban siendo formuladas. Leer la literatura solo en relación con la literatura, por ejemplo, resultaba una actividad relativamente pobre cuando se pensaba la literatura en un contexto algo mayor. La convicción de que los escritores no solo leían literatura y con solo esa biblioteca escribían sus textos, tenía que terminar por imponerse. Parece una conclusión obvia, pero no lo era tanto para una disciplina que a fuerza de análisis textuales - close readings - se había especializado en la interpretación de la forma escrita; en la consumación de la autonomía; en el placer de la escritura. Abolida (o debilitada) esa restricción, el mundo entero aparecía como disponible a la hora de pensar la literatura, el arte, la música, y por eso se impuso con tanta fuerza la idea de cultura que vino a imponerse, como una suerte de paraguas contenedor de las diferentes prácticas artísticas al mismo tiempo que del estudio que se hacía de ellas. A su vez, la estética, que había sido 'descubierta' en muchos otros rubros de la praxis cultural, le quitaba al arte su exclusividad y habilitaba su lectura en nuevos contextos, en correlación con otras experiencias.

Fue entonces cuando las bibliotecas comenzaron a cambiar. Digo bibliotecas en un sentido activo. Antes también incluían libros de arte, filosofía, música, medios; pero poco a poco los libros comenzaron a mezclarse y los libros mismos se volvieron más híbridos. Con esos cambios, las discusiones y las posibilidades de imaginar nuevos objetos también se desarrollaron en nuevas direcciones. El 
entrenamiento más generalizado en la escritura ocasionó también cierta desacralización a la hora de ponerse a escribir. El proceso fue posible gracias a la aparición de muchas nuevas formas de publicaciones, desde las editoriales independientes, interesadas en trabajos novedosos, hasta revistas académicas que cumplían con el doble papel de difundir el saber producido en las instituciones universitarias y, a la vez, de garantizar - a través de la normalización del curriculum vitae - la formación de una clase de investigadores profesionales, según parámetros globales. Los subsidios para publicaciones vinieron a colaborar oportunamente con este sistema.

Si pensamos en la literatura, y tomamos el caso argentino como ejemplo, hasta los años 9o, las editoriales que publicaban literatura argentina eran muy pocas y tenían exigencias insondables para los escritores jóvenes, a los que les costaba mucho publicar su primera novela ( $y$, naturalmente, seguir publicando). Con las sucesivas crisis, esas editoriales — que pertenecían, además, a conglomerados transnacionales - prácticamente dejaron de publicar literatura nueva y solo se quedaron con los escritores canónicos o de éxito garantizado. Lo bueno de aquella situación fue que pudieron proliferar editoriales independientes, que generaron espacios nuevos, no jerárquicos ni basados en criterios meramente mercantiles. Las políticas neoliberales, que en los años go destruyeron gran parte de las industrias nacionales en Argentina, desmantelaron el aparato editorial local, que fue vendido a empresas trasnacionales. La ausencia de grandes editoriales comerciales de capitales argentinos, que no respondieran a los catálogos de los conglomerados, generó un movimiento importante de editoriales alternativas, de pequeño volumen, que ocuparon el lugar que dejaron vacío las comerciales: aquellas editaron la literatura y los ensayos de escritores y críticos locales jóvenes, así como traducciones de ensayos o libros académicos de autores poco comerciales. Gran parte de la renovación estética, crítica, filosófica, se registró en un circuito cultural de sellos editoriales pequeños, no estandarizados, que se vendían solo en algunas librerías o en centros culturales, y que progresivamente se fueron imponiendo. Este desarrollo no se hizo al margen del mercado, sino según otra forma de circulación mercantil en la que las escalas eran más reducidas y el público más focalizado: pocos ejemplares, y distribución muy especializada en algunos circuitos alternativos. En medio del desarrollo de las nuevas tecnologías; del impacto de los blogs entre jóvenes escritores, críticos y lectores, y de la posibilidad de dar a conocer las obras casi inmediatamente a través de internet (posteriormente a través de los libros electrónicos), estas editoriales mantuvieron vivo un circuito en el que la literatura y la crítica decidieron trabajar desde un lugar de minoridad, oponiéndose (o, por lo menos, colocándose al margen) simultáneamente a 
(o ante) las ediciones exclusivamente comerciales y la circulación vía internet. En ese contexto, quizás oponerse no sea la palabra adecuada. Estas editoriales y los escritores y críticos que publicaron en ellas (muchos de los cuales participaban también de los otros circuitos) eligieron mantener una práctica que recuperaba experiencias muy modernas como, por ejemplo, impulsar una estética y un tipo de crítica particular (desarrollar un catálogo relativamente homogéneo); destacar la importancia de lo artesanal (cuidar los diseños de portadas y la materialidad del libro), e implementar nombres y textos relativamente alternativos (que no respondían a las precisas demandas del mercado de ese momento, dirigido por los grupos editoriales mayores). El pequeño movimiento editorial implicó no solo a la literatura, la crítica y el ensayo: galerías de arte, salas de teatro y música, grupos de cine, centros de experimentación estética y cultural generaron un circuito en donde fue posible cruzar prácticas y disciplinas; en donde los mismos actores funcionaban en más de un tipo de producción y, en muchos casos, las mezclaban. Las revistas digitales y, en otro sentido, las redes sociales, vinieron a agregar nuevos canales de circulación y, por tanto, de interlocución. Subsidios universitarios, premios, financiamientos institucionales y becas, permitieron también financiar revistas y libros. Si la escritura dejó de ser un problema central, si la publicación se volvió profesional, si las investigaciones comenzaron a circular entre una comunidad académica ampliada, como en un movimiento homeopático, la lectura comenzó a ocupar el lugar de aquello que necesitaba ser compensado, pensado como el lugar posible del problema.

Creo que toda esta situación hizo que la escritura — no solo la crítica- fluyera con cierta naturalidad. Es cierto que dejó de reclamar la complejidad que la había caracterizado, la sofisticación que la distinguía como una práctica escrituraria específica y no subsidiaria de la literatura. Pero se hizo más dialógica. $L a$ escritura crítica se hizo más legible, aunque no tenga lectores. No se trata de una paradoja - creo- sino de las nuevas condiciones de legibilidad, que se imponen cuando el acento está puesto en la circulación, entendida menos como recepción o lectura que como consumo. Creo que conviene no descuidar este aspecto. La crítica, que era una práctica muy minoritaria, comenzó también a formar parte del circuito del consumo.

¿Que no tiene lectores? ¿Quién los tiene? Las tiradas de los libros de literatura (que no son best-sellers) son muy pequeñas; los libros críticos y las revistas especializadas tienen una circulación aun menor. La aspiración a un público ampliado, que se amplía, no parece formar parte de este horizonte. La cuestión no es tener muchos lectores sino los lectores adecuados. La tradicional imagen de la mesa de luz con pilas de libros acumulados, que no se tiene tiempo de leer, 
sigue asomando como justificación o excusa cada vez que hay que confesar que no leímos tal libro. Pero no sé cuán real es. Leemos o miramos ciertos libros. A veces, no necesitamos leerlos para saber lo que son. Mencioné antes que creía que la idea de archivo había reemplazado la de biblioteca. Como todo cambio terminológico, se trata, en realidad, de un cambio en las prácticas de investigación y de lectura y, por lo tanto, en la forma en que escribimos. El archivo es el acopio, el uso, lo instituyente y conservador (para Jacques Derrida), y la máquina de sacralizar y aplebeyar los objetos y la experiencia (para Boris Groys). Al archivo no hay (necesariamente) que leerlo, solo construirlo, contemplarlo, analizarlo. Pero no pertenece al ámbito de la lectura. Nuestras investigaciones, cada vez más, invocan al archivo, lo conforman y, por tanto, se alejan de una relación directa con la escritura: no siempre la escritura es la mejor forma de comunicar los resultados de una investigación.

¿A quiénes leemos? ¿Cómo podemos hacer para leer todo lo que tenemos disponible, en la mesa de luz? La opción de encontrar en internet información que no cesa (sea veraz, confirmada, no corroborada, falaz), que se reproduce, que parece autogenerarse, que centra su principal valor en la disponibilidad, que permite combinar diferentes medios, podría estar arrasando con la capacidad de leer en el sentido más tradicional. Lecturas transversales, por palabras clave, por buscadores, concentran el foco en lo informativo. Los argumentos tienden a desaparecer en función de una acumulación de información, data, que viene a llenar una función de satisfacción en la mera búsqueda. A esto habría que sumar las licencias de Creative Commons, copyleft y las plataformas digitales, que ofrecen nuevas posibilidades de diseminar ideas. A los materiales y archivos digitalizados, ahora se agrega la posibilidad de la circulación digital. Con esta disponibilidad de materiales, también la práctica de la escritura se agita, es más 'fácil', más rápida, más instantánea. No se puede - y nadie quiere ni lo intenta - competir con lo que ofrece la web. Eso está fuera de cualquier pretensión crítica. Pero se pueden construir alternativas y servirse de todo aquello que nos ofrece la circulación.

La experiencia de participar en algunos de los sitios Academic Commons, que comenzaron a proliferar, puede dar algunas ideas. Cada mes, el servidor entrega un resumen de las visitas que recibieron tus textos, la cantidad de gente que bajó el PDF del artículo, un resumen que, como si se tratase de una cuenta bancaria, o de tarjeta de crédito, convierte la lectura también en data. Esa anonimia ha dejado de ser perturbadora; es, simplemente, una condición más de nuestro presente. Aquí ha habido un cambio. Cuando no sabemos quiénes nos leen, es difícil decir para quién escribimos. Aquí las comunidades lectoras no son fácilmente identificables porque los buscadores de internet tienen su propio sistema de asociaciones, que 
hacen emerger nombres y temas cuando menos se los espera, que trabajan con algoritmos que buscan según otras lógicas, que no pueden seguir los parámetros de una disciplina sino los de una combinatoria. También encuentran coincidencias más o menos esperables, obviamente, pero lo novedoso es, en todo caso, lo inesperado. En realidad, no buscamos lo que queremos encontrar sino que intentamos que lo menos tradicional nos salga al encuentro.

Es en este sentido que creo que la experiencia de lectura se ha diversificado tanto que afecta, necesariamente, la escritura. No leemos con la misma disciplina que antes de la red; no escribimos con las mismas pretensiones. Ya hace tiempo que vivimos en otro mundo. A la lectura tradicional se agrega hoy el modo más aleatorio de lo disponible en los innumerables sitios; el más frenético de los buscadores, el más distraído de la intermedialidad. No importa mucho qué pensemos de Wikipedia o de Google u otros buscadores; allí están siempre para empezar una búsqueda sobre lo desconocido, para corroborar un dato, para resolver una duda, para limitar un problema. Ya casi nadie se excusa de usarla.

Creo que escribimos, como siempre, para los que nos leen, aunque no sepamos quiénes son ni serán. Escribimos, también, porque - aunque de maneras muy diferentes- seguimos leyendo. Leemos porque la escritura ha seguido buscando caminos nuevos y la crítica, como práctica, se ha ido transformando.

\section{Instituciones}

Dentro de estos problemas, me interesaría, reconociendo la importancia de estas perspectivas, incorporar otra dimensión como marco de lectura de la literatura contemporánea escrita en español: el problema de las instituciones, como instancias decisivas en la construcción de campos literarios, estéticos, culturales; ellas son las mediadoras, las que, en los hechos, permiten que todo funcione y no siempre se reducen a formar parte del Estado o del mercado exclusivamente, y aun haciéndolo pueden también cumplir otras funciones. Las instituciones no siempre tienen la misma relación con el Estado ni con el mercado; se instalan en un arco muy variado que abarca desde aquellas que explícitamente responden a ellos (premios nacionales, premios de las editoriales, canon escolar, producción de best-sellers) hasta aquellas otras que oponen alguna resistencia o se conciben completamente en contra de ambos. Las instituciones - ya lo señaló muy claramente Michel Foucault- son los instrumentos de la capilaridad que transitan las formas del poder (o del contrapoder), las formas modernas en que se transmiten las órdenes sociales, vengan del Estado, de grupos corporativos, de grupos de resistencia política o de grupos más laxos, pero que quieren alguna forma de intervención social. 
Son, entonces, espacios en donde se articula la acción y, en la cultura contemporánea, después de adquirir un gran protagonismo (la redefinición de los museos, los premios editoriales, las bienales de arte, por ejemplo), están mostrando una cara más versátil. Dentro de las instituciones en donde la literatura se desarrolla, hay dos escenarios que, como dije, me interesa indagar: las editoriales alternativas y las universidades. Mi propuesta es pensar ambas como espacios de producción; no meramente como mediaciones entre autor, obra y lector, sino como espacios activos en donde la escritura también se acciona, se pone en movimiento, se desarrolla.

\section{Primero editar}

Las políticas neoliberales, que en los años 80 y 90 destruyeron, en varios países latinoamericanos, gran parte de las industrias nacionales, desmantelaron parcial o totalmente los aparatos editoriales locales, que fueron vendidos a empresas trasnacionales (los trabajos de Pablo Sánchez y José Ignacio Padilla iniciaron estos estudios). La ausencia de grandes editoriales comerciales de capitales locales (excepto en México), que no respondieran a los catálogos de los conglomerados, generó un movimiento importante de editoriales alternativas (con epicentro especial en Argentina). El pensamiento de intelectuales como Jacques Rancière, Antonio Negri, Alain Badiou y Paolo Virno, activos en la esfera pública, se presentó a los lectores a través de editoriales pequeñas como Tinta Limón, Cactus (Argentina) o Traficantes de sueños (España, que publica los textos con licencia Creative Commons and copyleft). Y también los han publicado otras editoriales, de mayor volumen, como Adriana Hidalgo y Manantial (Argentina) que, sin embargo, no pertenecen a los grandes conglomerados editoriales. El pensamiento alternativo no es fácilmente comercializable, pero supo crear sus propios circuitos. Algo parecido sucedió con las librerías. Una vez que el mercado del libro se concentró en cadenas de venta, comenzaron a surgir pequeñas librerías locales, especializadas según los nuevos públicos, que eran casi las únicas que vendían los libros de las editoriales alternativas (también surgieron distribuidoras para ese nuevo mercado del libro). Estas editoriales son, obviamente, parte del mercado pero apuestan a una renovación y su actividad no está solo enfocada en la ganancia, sino en combinarla con proyectos estéticos o intelectuales.

Uno de los nuevos intereses críticos fue el estudio de las formas de circulación de la literatura. Si la interrogación por los sentidos de las obras marcó buena parte de lo que la crítica hizo a lo largo del siglo XX, nuevas investigaciones se ocupan ahora, no de la producción y el sentido, sino 
de los recorridos y circulaciones. Un ejemplo es el de quienes estudian las editoriales cartoneras de América Latina. Lideradas por Eloísa Cartonera, de Argentina, estas editoriales abrieron un campo nuevo de producción y circulación, no solo para la literatura latinoamericana sino también para sus críticos que encontraron en ellas un novedoso instrumento para pensar la novedad de los fenómenos culturales que mostraban una alternativa a las formas neoliberales de difusión cultural. Las editoriales cartoneras abrieron un campo nuevo para pensar la literatura, y recibieron un impulso importante cuando la academia comenzó a fijarse en ellas, pues dejaron de ser fenómenos locales para despertar intereses globales. Estas editoriales también terminaron por globalizar una experiencia al diseminar su modelo de relación con la literatura. Quienes las estudian forman un grupo relativamente pequeño pero fuerte en la composición de un discurso crítico sobre las nuevas formas editoriales. Este es solo un ejemplo de cómo se reinventó la relación crítica con la literatura durante la última década.

El discurso crítico, especialmente el que se desarrolla en las universidades, ha apoyado estos procesos de consolidación de un circuito que comenzó siendo alternativo. Si bien el canon no ha perdido su lugar hegemónico en la Academia, desde el ingreso de los estudios culturales a fines de los 80 , las formas alternativas al canon fueron ganando espacios muy rápidamente, canonizándose en algunos casos, generando zonas de novedad en otros. Esta suerte de refugio generó un interesante movimiento de ida y vuelta entre crítica y literatura. Muchas novelas contemporáneas han comenzado a hacer crítica dentro mismo de la ficción. Esto no es nuevo (parece, en cierto modo, condición de la narración desde el Quijote); sin embargo, adquiere un nuevo sentido porque vuelve a la literatura, cada vez más, una cuestión de especialistas que dialogan entre sí. El sueño de la literatura para públicos masivos, que el boom de los años 60 había casi concretizado, hoy no puede ver sino su inversión: la literatura comercial sigue su camino, pero se sigue produciendo una literatura que es, cada vez más, para especialistas.

\section{Después criticar}

Las universidades se han vuelto globales, al ritmo de creación de un mercado académico. Congresos internacionales, publicaciones con los mismos o parecidos criterios de evaluación, acceso a $e$-books (o distribución informal de textos en formatos como PDF), generan también una dinámica que pone en contacto el discurso crítico con toda la novedad del circuito alternativo. Con vocación alternativa ella misma, la academia, que hace tiempo suscribió el desarrollo de los 
estudios culturales como forma de abandonar la filología y de establecer cruces transdisciplinarios, se acopla al movimiento de descanonización de la crítica. Al hacerlo, contribuye a formar parte de la red que otorga prestigio a las nuevas producciones, toda vez que se propone identificar nuevos objetos de estudio. Como institución, la academia solía ir muy por detrás de los movimientos del mercado y de la propia institución literaria; pero ya se ha ido acoplando a los ritmos más rápidos de lo contemporáneo.

Durante los años 9o, la mayoría de las universidades latinoamericanas comenzaron un proceso de profesionalización en el que el desarrollo de la teoría como disciplina jugó un rol central. Los recursos económicos variaron de país en país y, a pesar de no haber sido siempre significativos, sí se experimentó un proceso de profesionalización de las humanidades que derivó en un progresivo desarrollo teórico de buena parte de las investigaciones, pues este era requisito para la obtención de puestos, jerarquización y dinero para investigación. No es que la teoría haya servido (necesariamente) para escalar puestos en la academia sino que debió desplazar su sentido y conformar desde entonces nuevos objetos de estudio. Una versión institucional, llena de contenidos teóricos se estratificó en las universidades; pero el interés teórico fue indagando nuevas cuestiones. La aparición de nuevos espacios propicios para la producción de saber - no necesariamente de grandes recursos económicos - ha tenido mucho que ver con fuertes momentos de implicación del pensamiento teórico. Pero ese pensamiento no decayó - sino al contrario - cuando las condiciones fueron adversas e incluso represivas. Por eso, la teoría no se opone a la institucionalización del saber aunque en principio la cuestione. Creo que esta paradoja constituyó un campo que, en la academia, conforma el estado actual de la crítica de la literatura: todos somos alternativos, pero ahora lo somos en las instituciones que, por no representar un espacio unificado de saber, pueden interactuar de manera más libre con otras formas de producción de saber.

Si bien no se puede generalizar sobre los tópicos que se estudian en la academia, sin embargo, podemos decir que está sujeta a ciertas demandas disciplinarias que ordenan, clasifican y promueven temas. Basta mirar los programas de congresos como los de la Latin American Studies Association (LASA). Esta institución profesional de Estados Unidos, como hay tantas en el país según las disciplinas, fue fundada en 1966. En los últimos años sufrió un gran incremento en el número de miembros y también en la cantidad de propuestas para congreso (a raíz de lo cual, en el año 2012 se cambió la frecuencia de las reuniones: de 18 meses a 12 para dar cabida a todos los miembros que querían participar). Aunque en las primeras décadas la membresía no estaba 
limitada a académicos de USA, el número de latinoamericanos residentes en América Latina realmente se incrementó en los últimos años. En menor medida también creció la membresía de latinoamericanistas europeos y asiáticos. En su página web aparece la siguiente declaración:

La Asociación de Estudios Latinoamericanos (LASA) es la asociación profesional más grande del mundo que reúne a individuos e instituciones dedicados al estudio de Latinoamérica. Con más de 7.000 miembros, de los cuales el cuarenta y cinco por ciento reside fuera de Estados Unidos, LASA es la asociación que reúne a los expertos en Latinoamérica de todas las disciplinas y a diversas áreas ocupacionales en todo el mundo.

Las disciplinas que tienen mayor representación son ciencias políticas, en primer lugar y literatura en segundo (le siguen historia, antropología y arqueología y sociología). En estos congresos es posible encontrarse cada año con una actualización de los temas de investigación predominantes. Ellos funcionan como la superficie de contacto de los trabajos que se realizan especialmente en Estados Unidos y los países de América Latina y que, obviamente, tienden a homogeneizar los intereses y propuestas. Cualquier asociado puede proponer una mesa; pero las propuestas están sujetas a la aprobación de un comité de expertos que quienes presiden el congreso nombran cada año. La selección se hace teniendo en cuenta los criterios profesionales que regulan la producción de un saber que cada vez es más parecido en todos los centros universitarios. Los congresos son una parte importante, pero lo son aun más las revistas especializadas. También ellas se ven obligadas, por cuestiones profesionales, a uniformar criterios de calidad académica y, con ello, temas de investigación. Casi nadie, en el mundo académico, quiere quedar fuera de los parámetros que garantizan permanencia en el trabajo y continuidad en la investigación. Las revistas online, que han ganado prestigio con los años, son una forma de difusión que también ha cambiado el carácter nacional de las publicaciones y las ha abierto a un diálogo profesional-transnacional. Becas, acceso a bibliotecas online, proyectos en colaboración y pasantías completan el cuadro de constitución de una suerte de lengua franca de la crítica literaria en español que, a la vez que crea debates transnacionales y transdisciplinarios, genera una notable homogeneización temática. Como siempre, existen las posibilidades de evadir las nuevas hegemonías a través de nuevos objetos, pero no todos los actores del campo crítico pueden tomar esos riesgos por las precarias condiciones de trabajo en que muchos se encuentran. El mercado académico mueve, sin embargo, mucha gente. Y con ella, los temas viajan y se reproducen. 
Si atendemos a esta suerte de estado de la cuestión, vemos que se ha ido estableciendo cierta idea de homogeneidad pero que, al mismo tiempo, las condiciones de centralización del mercado (editorial y académico) han generado también nuevas posibilidades de crear alternativas a la uniformidad del paisaje literario. Creo que esas alternativas, extremadamente variadas como pueden ser, tienen algunos aspectos en común. Me interesa mencionar dos: la idea de comunidad y el carácter proyectual de muchos emprendimientos. Construir comunidad podría ser el signo de una alternativa a las presiones de uniformidad; en tanto, el carácter proyectual dinamiza las nuevas prácticas de modo que puedan siquiera intentar evadir la casi obligatoria institucionalización. Hubo un tiempo en que la pretensión de todo grupo estético o intelectual era imponerse, ganar un territorio y establecerse. Hoy, cuando casi todo es pasible de ser colonizado por el mercado o las instituciones, trabajar con la conciencia de la deserción, de ser capaz de abandonar lo que se ha creado, es un desafío que muchos intentan asumir (la idea de deserción la desarrolla Paolo Virno como una forma de crear alternativas a las políticas de integración o de confrontación). Y en ese desafío puede residir la posibilidad de crear alternativas. Dentro de esta ecología crítica contemporánea, sí parece posible crear alternativas, en la literatura y en la academia, como lo demuestran muchas prácticas contemporáneas. 